\title{
Polimixina B: efeito dose e tempo dependente na nefrotoxicidade in vitro
}

\author{
Polymyxin B: dose and time dependent nephrotoxicity effect in vitro
}

Luciana Barros de Moura Neiva ${ }^{1}$

Cassiane Dezoti da Fonseca ${ }^{1}$

Mirian Watanabe ${ }^{1}$

Maria de Fátima Fernandes Vattimo ${ }^{1}$

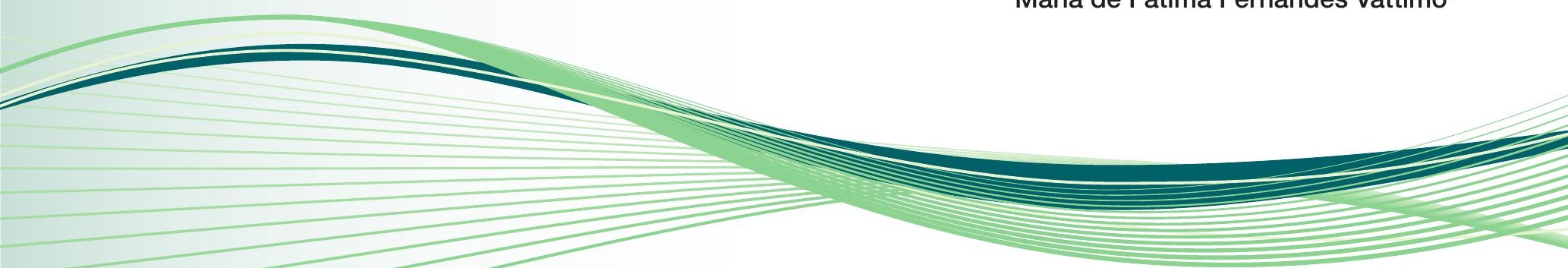

Descritores

Polimixina B; Lesão renal aguda; Células LLC-PK1; Apoptose

Keywords

Polymyxin B; Acute kidney injury; LLCPK1 cells; Apoptosis

Submetido

19 de Abril de 2012

Aceito

21 de Fevereiro de 2013

\section{Resumo}

Objetivo: Caracterizar a toxicidade da polimixina B (PmxB) em células renais em dosagem e tempos diferentes. Métodos: Células LLC-PK , cultivadas em placas multiwell de 12 poços, foram divididas nos seguintes grupos: Controle (CTL) - células mantidas em meio DMEM suplementado a 5\%; G1 - células expostas à concentração de $75 \mathrm{mM}$ de PmxB; G2 - células expostas à concentração de $375 \mathrm{mM}$ de PmxB. Cada grupo foi avaliado nos tempos de 24, 48 e 72 horas quanto à viabilidade celular (Acridine Orange/ Brometo de Etídio) e apoptose (Hoechst 33342).

Resultados: Os dados demonstraram a viabilidade celular e a apoptose à exposição de três doses de PmxB em três intervalos de tempo, com um aumento significativo da toxicidade à elevação das doses e ao maior tempo de permanência no antibiótico para apoptose.

Conclusão: A citotoxicidade pela PmxB, no modelo de cultivo celular, se mostrou tempo e dose dependente, aumentando com a maior exposição e maior dose de antibiótico.

\section{Abstract}

Objective: To characterize the toxicity of polymyxin B (PmxB) in renal cell in different dosage and times.

Methods: LLC-PK1 cells grown in 12 well multiwell plates were divided into the following groups: Control

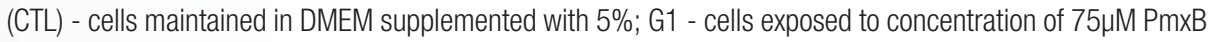

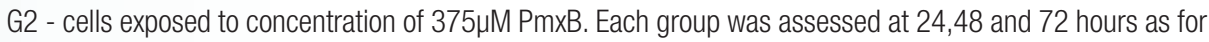
cell viability (Acridine orange/ethidium bromide) and apoptosis (Hoechst 33342).

Results: The data demonstrate the cell viability and apoptosis exposure of three doses of PmxB in three time intervals, with a significant increase in toxicity to high doses and longer duration of stay in the antibiotic to apoptosis.

Conclusion: Cytotoxicity by PmxB in cell culture model, showed to be time and dose dependent, increasing with increased exposure and higher dose of antibiotic.

\section{Autor correspondente}

Maria de Fátima Fernandes Vattimo Av. Dr. Enéas Carvalho de Aguiar, $n^{\circ}$ 419, Cerqueira César, São Paulo, SP, Brasil. CEP: 05403-000 nephron@usp.br
${ }^{1}$ Escola de Enfermagem, Universidade de São Paulo, São Paulo, SP, Brasil. Conflitos de interesse: não há conflitos de interesse a declarar. 


\section{Introdução}

Estudos epidemiológicos recentes relacionam as drogas nefrotóxicas com $19 \%$ a $25 \%$ dos casos de lesão renal aguda (LRA). ${ }^{(1)} \mathrm{A}$ aplicabilidade de agentes potencialmente nefrotóxicos no ambiente hospitalar é inevitável, em virtude da ocorrência cada vez mais freqüente de microorganismos multirresistentes. Outro agravante relaciona-se ao fato de que a lesão renal aguda nefrotóxica é subestimada como um fator causador e possivelmente modificável de LRA. ${ }^{(1)}$

Dentre os fármacos nefrotóxicos destacam-se o grupo das polimixinas. Das cinco (polimixinas $\mathrm{A}, \mathrm{B}, \mathrm{C}, \mathrm{D}$ e E) apenas a polimixina $\mathrm{B}(\mathrm{PmxB})$ e a polimixina $\mathrm{E}$ tem sido utilizadas no ambiente intra-hospitalar. Relevante ressaltar que a polimixina $\mathrm{E}$ apresenta potencial nefrotóxico inferior ao da $\operatorname{PmxB}$, em contrapartida, a ação bactericida da PmxB é mais expressiva. ${ }^{(2)}$

A composição do sulfato de polimixina B, também conhecido como polimixina B ou Aerosporin, consiste em uma mistura de sulfatos de polimixina $\mathrm{B}_{1}$ e polimixina $\mathrm{B}_{2} \cdot{ }^{(2-4)}$ Por atuar na membrana citoplasmática, a PmxB compromete as propriedades osmóticas e os mecanismos de transporte da membrana celular, uma vez que a composição dessa estrutura na bactéria e na célula humana é semelhante. ${ }^{(2-5)}$

Esse antimicrobiano pode se acumular em vários órgáos e tecidos, como rim, fígado, cérebro, pulmôes, coração e músculos por um período de até cinco dias. ${ }^{(2-4)}$ Já a excreção deste agente farmacológico se dá, principalmente, pelos rins, onde $60 \%$ do medicamento pode ser encontrado na urina. Na ocorrência de lesão renal sua meia-vida pode aumentar para dois ou três dias. Nefrotoxicidade, neurotoxicidade e reaçóes de hipersensibilidade constituem-se como seus efeitos tóxicos mais característicos. ${ }^{(2-4)}$

Estudos experimentais têm demonstrado que a porção lisa do túbulo proximal (segmento S3) é a mais suscetível à lesão isquêmica ou nefrotóxica. As células nesta parte do néfron perdem a borda em escova tubular normal e sofrem necrose celular extensa. As células tubulares proxi- mais no córtex (segmentos S1 e S2) são menos suscetíveis à lesão, tendo sido observado menos necrose que nas células do segmento S3. Apesar do uso freqüente do termo necrose, a apoptose, outro mecanismo de morte celular, também está presente na lesão celular das LRAs isquêmica e nefrotóxica. Por outro lado, dados histológicos concretos que evidenciem a necrose em túbulos renais não estão disponíveis até o momento. Isso pressupóe que sua manifestação esparsa e variável seja responsável, em parte, pelo dano funcional precipitado na LRA. ${ }^{(1,6)}$

As células tubulares renais apresentam reaçóes potenciais à lesão renal. A lesão celular subletal pode levar à disfunção celular, à expressão gênica alterada, à desdiferenciação celular e, finalmente, à recuperação da função celular. ${ }^{(6)}$

A lesão celular letal, no caso da LRA, quando não restabelecida a homeostase, pode levar à necrose e a apoptose. As características morfológicas bem como os mecanismos que envolvem os processos de necrose e apoptose são consideravelmente distintos. ${ }^{(1,6)}$

Na LRA, a apoptose e a necrose podem ser provocadas pelos mesmos eventos citotóxicos. Parece claro que a apoptose é uma resposta à injúria de células lesadas submetidas a uma pequena isquemia ou a toxinas em baixas concentraçôes em relação àquelas que induziriam colapso metabólico rápido e necrose. Alguns estudos demonstram que o mecanismo de morte celular tubular renal parece depender da severidade da lesão. ${ }^{(1)}$

$\mathrm{Na}$ tentativa de simular efeitos nefrotóxicos desta droga in vitro, as células LLC-PK , células epiteliais tubulares proximais, foram a linhagem de escolha. Obtidas a partir do porco Hampshire, possuem muitas características morfológicas do epitélio renal, como microvilos apicais, tightjunctions, envoltórios da membrana basolateral. Apresentam ainda um fenótipo predominantemente proximal, constituindo, dessa forma, um modelo seguro para avaliar nefrotoxicidade. $^{(1,6)}$

Organismos cada vez mais multirresistentes à antibioticoterapia convencional tem levado ao resgate da PmxB que assumiu importante papel farmacoterapêutico nos últimos anos, e não surpreendentemente, já manifesta efeitos indesejáveis à se- 
melhança de medicamentos bem estabelecidos na clínica. Esta associação de fatos justificou estudos como estes em que se desenvolveram experimentos de nefrotoxicidade com a PmxB. Tendo em vista tais consideraçóes, o objetivo deste trabalho foi caracterizar a toxicidade da $\mathrm{PmxB}$ em células renais.

\section{Métodos}

Estudo quantitativo experimental in vitro realizado no Laboratório Experimental de Modelo Animais da Escola de Enfermagem da Universidade de São Paulo (LEMA - EEUSP) e no laboratório de Biologia Celular e Molecular da Disciplina de Nefrologia da Universidade Federal de Sáo Paulo (UNIFESP).

Foram utilizadas células LLC-PK 1 , uma linha epitelial tubular proximal de porco, passagem 40, obtidas da American Tissue Cells Collection (ATCC), que foram retiradas de um counteinerde nitrogênio, descongeladas e mantidas em garrafas de cultura contendo Dulbecco's Modified Eagle's Medium (DMEM) com soro bovino fetal (SBF) a 5\%.

As células LLC-PK, cultivadas em placas multiwell de 12 poços, foram divididas nos seguintes grupos: Controle (CTL) - células mantidas em meio DMEM suplementado a 5\%; G1 - células expostas à concentração de $75 \mathrm{mM}$ de polimixina B; G2 - células expostas à concentração de $375 \mathrm{mM}$ de polimixina B. Cada grupo foi avaliado nos tempos de 24, 48 e 72 horas quanto à viabilidade celular e apoptose.

Células tubulares proximais foram cultivadas em garrafas de cultura de $25 \mathrm{~cm}^{2}, 75 \mathrm{~cm}^{2}$ ou placas multiwell de12 poços, de acordo com o protocolo experimental, em meio Dulbecco's Modified Eagle's Medium (DMEM) suplementado com o soro fetal bovino (SFB 5\% v/v), $\mathrm{NaHCO}_{3}$ 2,0g/L, HEPES $2,6 \mathrm{~g} / \mathrm{L}$, penicilina $10.000 \mathrm{UI} / \mathrm{L}$, estreptomicina 50 $\mathrm{mg} / \mathrm{L}$ e neomicina $100 \mathrm{mg} / \mathrm{L}$ e mantidas na incubadora a $37^{\circ} \mathrm{C}$ com $95 \%$ de ar e $5 \%$ de $\mathrm{CO}_{2}$. Ao atingirem $80 \%$ de confluência, as células foram descoladas da garrafa por tripsinização e a atividade de tripsina neutralizada com DMEM contendo SFB. As células foram utilizadas na manutenção das culturas ou na realização dos protocolos experimentais, sendo que cada protocolo foi repetido pelo menos oito vezes. Estoques de células foram congelados sempre na passagem 40 para manutenção de uniformidade nos experimentos.

A viabilidade celular foi determinada pela exclusão dos corantes fluorescentes acridineorange e brometo de etídio (Sigma). ${ }^{(7)}$ Para a leitura da viabilidade foram utilizados apenas $10 \mathrm{~mL}$ da suspensão de células tripsinizadas que foram misturadas a $0,3 \mathrm{~mL}$ da solução dos corantes acridineorange e brometo de etídio $(100 \mathrm{mg} / \mathrm{ml})$, numa relação v:v (1:1). O método de contagem de células viáveis baseia-se na captação seletiva dos corantes citados, que é dependente da integridade da membrana plasmática. O brometo de etídio passa pela membrana íntegra, ligando-se ao DNA celular e, emitindo fluorescência na cor verde (excitação 460nm e emissão650 nm) indicando as células viáveis. $\mathrm{O}$ acridineorange cora o RNA, porém não passa pela membrana íntegra, sendo captado apenas pelas células cuja membrana esteja danificada e fluoresce na cor laranja-avermelhado (excitação $510 \mathrm{~nm}$ e emissão $595 \mathrm{~nm}$ ), mostrando quais células estão inviáveis (necrose). Ao final, foi realizada a contagem de no mínimo de 200 células para cada representante de grupo por meio de microscópio de fluorescência (ampliação de 40x e 200). Os resultados foram expressos em porcentagem de células viáveis.

Essa avaliação de apoptose consiste no método morfológico, quantitativo Hoechst 33342 [Bisbenzimide HOE 33342 (2'-[4-etoxifenil]-5-[4-metil1-piperazinil]-2,5'-bi-1H-benzimidazol tricloridrato)], que é um corante específico para adenina - timina. Esse corante é facilmente absorvido pela célula, corando o DNA, os cromossomos e o núcleo, possibilitando a visualização de corpos apoptóticos à microscopia de fluorescência em coloração azul intensa. Para a avaliação de apoptose foi preparada uma solução $100 \mathrm{mg} / \mathrm{mL}$ do corante Hoescht 33342 em PBS. As células foram submetidas ao mesmo preparo descrito para a avaliação da viabilidade, para obtençáo do precipitado celular. $\mathrm{Na}$ lâmina foram pipetados $5 \mathrm{~mL}$ do Hoescht 33342 adicionados a $5 \mathrm{~mL}$ da suspensão de células. A lâmina foi armazenada por 10 minutos, à temperatura ambiente e na ausência de luz, para 
coloração da cromatina. ${ }^{(8)}$ Procedeu-se, então, a contagem de 100 a 200 células para cada grupo. Os resultados foram expressos em porcentagem de células apoptóticas em relação ao total de células.

A metodologia estatística aplicada consistiu em Análise de Variância-ANOVA. Neste modelo, todas as interaçóes foram testadas. Quando detectadas diferenças, realizaram-se as comparaçôes múltiplas por meio do teste de Bonferroni e Tukey. As estatísticas com p descritivo $\leq 0,05$ foram consideradas significantes. Os dados foram definidos como média \pm erro padrão e serão apresentados na forma de tabelas.

\section{Resultados}

Os dados referentes a tabela 1 demonstraram a viabilidade celular à exposição de duas doses de PmxB em três intervalos de tempo, com aumento significativo da toxicidade à elevação das doses em 24 horas, em 48 horase em 72 horas.

Tabela 1. Viabilidade de células LLC-PK ${ }_{1}$ em relação ao tratamento com Polimixina B

\begin{tabular}{llccc}
\hline \multicolumn{5}{c}{$\begin{array}{c}\text { Viabilidade celular (\%) } \\
\text { Tempo (horas) }\end{array}$} \\
$\begin{array}{l}\text { Grupos } \\
\text { (mM) }\end{array}$ & $\mathbf{n}$ & $\mathbf{2 4}$ & $\mathbf{4 8}$ & 72 \\
\hline CTL & 8 & $80,7 \pm 3,4$ & $80,9 \pm 1,9$ & $81,4 \pm 5,8$ \\
G1 & 8 & $57,6 \pm 7,7^{\mathrm{a}}$ & $56,9 \pm 8,1^{\mathrm{a}}$ & $56,9 \pm 2,9^{\mathrm{a}}$ \\
G2 & 8 & $41,0 \pm 6,7^{\mathrm{ab}}$ & $41,3 \pm 9,7^{\mathrm{ab}}$ & $40,9 \pm 2,0^{\mathrm{ab}}$ \\
\hline
\end{tabular}

Legenda: $\mathrm{CTL}=0 \mu \mathrm{M} ; \mathrm{G} 1=75 \mu \mathrm{M} ; \mathrm{G} 2=375 \mu \mathrm{M} ;{ }^{\text {ap }}<0,05$ vs CTL $-24 \mathrm{~h} / 48 \mathrm{~h} /$ $72 \mathrm{~h} ;{ }^{\text {b }} \mathrm{p}<0,05$ vs G1 $-24 \mathrm{~h} / 48 \mathrm{~h} / 72 \mathrm{~h}$

$\mathrm{Na}$ tabela 2 os dados apresentam a apoptose de células LLC-PK 1 expostasaos grupos e tempos já mencionados. A elevação da dose (grupo) aumentou a população de células em apoptose em 24 horas, 48 horas e 72 horas. Isso demonstra que a resposta celular foi a mesma com a elevação da dose de PmxB: maior número de células morreram por apoptose. De forma geral, constatou-se diferença significativa em todos os tempos oque demonstra maior toxicidade, pois à medida que o tempo de exposição e a dose da $\mathrm{PmxB}$ são aumentados, maior número de células entram em apoptose.
Tabela 2. Apoptose de células LLC-PK ${ }_{1}$ em relação ao tratamento com Polimixina B

\begin{tabular}{|c|c|c|c|c|}
\hline \multirow[b]{2}{*}{$\begin{array}{l}\text { Grupos } \\
\text { (mM) }\end{array}$} & \multirow[b]{2}{*}{$\mathrm{n}$} & \multicolumn{2}{|c|}{$\begin{array}{l}\text { Apoptose (\%) } \\
\text { Tempo (horas) }\end{array}$} & \multirow[b]{2}{*}{72} \\
\hline & & 24 & 48 & \\
\hline CTL & 8 & $4,5 \pm 1,2$ & $8,6 \pm 5,3$ & $8,9 \pm 2,1$ \\
\hline G1 & 8 & $20,7 \pm 2,4^{\mathrm{a}}$ & $24,9 \pm 2,6^{a}$ & $28,0 \pm 2,7^{\mathrm{ac}}$ \\
\hline G2 & 8 & $29,9 \pm 2,6^{\mathrm{ab}}$ & $32,7 \pm 3,1^{\mathrm{ab}}$ & $36,1 \pm 3,8^{\text {abd }}$ \\
\hline
\end{tabular}

Legenda: $\mathrm{CTL}=0 \mu \mathrm{M} ; \mathrm{G} 1=75 \mu \mathrm{M} ; \mathrm{G} 2=375 \mu \mathrm{M} ;{ }^{\mathrm{a}} \mathrm{p}<0,05$ vs $\mathrm{CTL}-24 \mathrm{~h} / 48 \mathrm{~h}$ $/ 72 \mathrm{~h} ;{ }^{b} \mathrm{p}<0,05$ vs G1 $-24 \mathrm{~h} / 48 \mathrm{~h} / 72 \mathrm{~h} ;{ }^{\circ} \mathrm{p}<0,05$ vs G1 $-24 \mathrm{~h} ;{ }^{d} \mathrm{p}<0,05$ vs G2 - $24 h$

\section{Discussão}

Os resultados mostraram que o efeito citotóxico da PmxB se intensificou com a elevação da dose daquele fármaco. Esse achado foi constatado uma vez que as

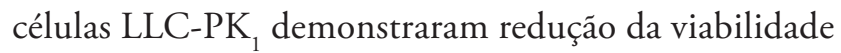
quando submetidas a uma dose cada vez mais alta da PmxB. Inversamente, com a elevação da dose do antibiótico a população de células apoptóticas aumentou, demonstrando como a célula reage ao efeito tóxico da injúria, ou seja, a presença de um fenômeno biológico cada vez maior se a injúria também for maior. Modelos in vitro que mimetizam a toxicidade pela $\mathrm{PmxB}$ em células renais não são comuns. Seu mecanismo de ação na lesão renal aguda não está esclarecido. ${ }^{(1)}$ Devido aos esclarecimentos inconclusivos quanto aos mecanismos celulares envolvidos na gênese desse efeito colateral, esta investigação, por meio de técnicas de cultura de células imortalizadas renais, avaliou os efeitos da PmxB.

Esses achados confirmaram o efeito tóxico dose dependente deste antibiótico, o que na clínica pode pressupor que uma concentração inibitória elevada como medida terapêutica pode ser representar risco de morte celular renal com eventual conseqüência funcional.

Além da dose, o tempo de permanência da droga nas células influenciou o mecanismo de morte celular. Quanto maior tempo as células foram expostas à toxicidade dapolimixinamaior apoptose foi observada.

Tem sido sugerido que o mecanismo de nefrotoxicidade pela $\mathrm{PmxB}$ é conseqüência do aumento da permeabilidade da membrana celular, o que resulta em influxo aumentado de cátions, ânions e 
água, levando ao edema e lise celular. ${ }^{(9)} \mathrm{A} \mathrm{PmxB}$ atua na membrana plasmática da bactéria, prejudicando mecanismos de transporte. Sua ação não é seletiva, podendo também atuar na membrana celular de outros organismos. Seu efeito terapêutico depende da concentração inibitória mínima para bactéria infectante. ${ }^{(10)}$

A nefrotoxicidade da PmxB é um problema clínico pouco freqüente em pacientes com função renal adequada e está relacionada à dose administrada desta droga. ${ }^{(10)}$ Estudos sobre o uso tópico ou o uso parenteral diário de $\mathrm{PmxB}$ na dose de $2.5 \mathrm{mg} . \mathrm{kg} \mathrm{g}^{-1}$ causou proteinúria, hematúria e formação de cilindros em alguns casos. ${ }^{(10,11)}$

Evidências demonstram que a PmxB apresenta ação bactericida mais eficaz in vitro que in vivo, por isso aconselha-se que durante a terapia parenteral os níveis séricos sejam avaliados e mantidos abaixo de $10 \mathrm{mg} \cdot \mathrm{1}^{-1} \cdot{ }^{(10)}$

Um estudo recente realizado em ambiente intra -hospitalar com 60 pacientes investigou com maior ênfase o seu efeito nefrotóxico. Os seguintes critérios foram considerados: características demográficas, doenças de base, ambientes de infecção, microorganismos, duração da permanência, dosagem de $\operatorname{PmxB}$, freqüência e duração da dose, outras medicaçôes administradas, creatinina sérica, desenvolvimento de alteraçôes neurológicas e cutâneas, e resultados microbiológicos e clínicos. A taxa de mortalidade total foi de $20 \%$. Entre os pacientes que desenvolveram lesão renal, o índice de mortalidade foi de $57 \%$, e o índice de mortalidade dos pacientes que não desenvolveram lesão renal foi de $15 \%$. Do grupo que desenvolveu lesão renal, três sobreviveram; destes, dois restabeleceram a função renal e um necessitou de terapia de substituição renal. Contradizendo estudos mais antigos onde os índices de nefrotoxicidade variavam de 17 a $100 \%$, a $\mathrm{PmxB}$ foi bem tolerada pela maioria dos pacientes; destes, $14 \%$ desenvolveram nefrotoxicidade. Sua aplicação proporcionou eficácia clínica e microbiológica, com menor comprometimento da função renal. ${ }^{(12)}$

Outro estudo sobre PmxB enfatiza novamente sua nefrotoxicidade, mas proporciona uma nova abordagem sobre este antimicrobiano. A endotoxina é um lipolissacarídeo (LPS) encontrado na membrana externa de bactérias gram-negativas. A PmxB liga-se a endotoxina, neutralizando sua atividade, que inclui morte celular. A PmxB nonapeptídeo é um derivado da $\mathrm{PmxB}$ que controla atividade anti-lipolissacarídeo, mas com característica menos tóxica. Nesse trabalho experimental, cães que receberam elevadas doses de $\mathrm{PmxB}$ apresentaram hipertermia, rubor facial e abdominal, além de aumento de nitrogênio uréico e creatinina sérica. Tais alteraçóes não foram observadas nos animais controle nem naqueles que receberam dose igual de PmxB nonapeptídeo. Ratos Sprague-Dawley que receberam dose de PmxB desenvolveram dispnéia, cianose, diminuição da atividade física e ataxia. No grupo controle ou no grupo em que foi administrada a $\mathrm{PmxB}$ nonapeptídeo essas alteraçôes não foram registradas. É importante ressaltar que a $\mathrm{PmxB}$ nonapeptídeo não apresenta atividade antibiótica, mas é capaz de desestruturar a membrana de bactérias gramnegativas, demonstrando que a estrutura química dissociada do efeito antimicrobiano da PmxB é que mostra ter relação com sua toxicidade. ${ }^{(13)}$

Importante enfatizar que a detecção de apoptose no modelo aqui desenvolvido padroniza o evento tóxico induzido pela PmxB. A apoptose é um evento coordenado que atua em processos fisiológicos, como a homeostase tecidual, desenvolvimento embrionário e resposta imune. $\mathrm{O}$ ciclo mitótico e a apoptose apresentam características semelhantes. Por isso, o estudo e o entendimento deste fenômeno na LRA isquêmica e nefrotóxica podem proporcionar direcionamentos para medidas de prevenção ou recuperação eficientes.

Há que se ressaltar que a prevenção de sucesso na LRA exige o conhecimento dos mecanismos patogênicos envolvidos, da identificação dos fatores de risco individuais e de medidas pré emptivas associadas à vigilância e intervenção precoce. Nesse contexto incentivam-se modelos de investigação sobre as alteraçóes celulares envolvidas no distúrbio funcional precipitado pelas nefrotoxinas, como a PmxB.

Esta pesquisa possibilitará à Enfermagem correlacionar a pesquisa básica à pesquisa clínica permitindo, a este profissional uma compreensão mais 
aprimorada dos mecanismos biológicos, fisiológicos e patológicos que a acometem a LRA nefrotóxica pela PmxB, além do estabelecimento de medidas de prevenção e/ou nefroprotetoras.

O presente trabalho permitirá o estabelecimento protocolos de modelos in vitro; reconhecimento de modelo de nefroproteção a partir de técnicas de biologia celular e molecular; interpretação dos eventos moleculares, celulares e fisiopatológicos da LRA nefrotóxica a partir de estudos com culturas de células; identificação precoce de situações clínicas que exerçam influência na ocorrência da disfunção renal; compreensão das terapêuticas utilizadas no tratamento do paciente com disfunção renal; identificação dos fatores de risco relacionados à ocorrência da LRA nefrotóxica pela PmxB; elaboração de medidas preventivas para a LRA pela PmxB e o estabelecimento de estratégias clínicas para minimizar a ocorrência da LRA nefrotóxica pela PmxB.

\section{Conclusão}

A PmxB confirmou seu efeito citotóxico em células

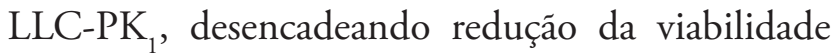
e elevação da apoptose à medida que se elevou a dose e o tempo do antibiótico. A citotoxicidade pela PmxB, no modelo de cultivo celular, se mostrou tempo e dose dependente, aumentando com a maior exposição e maior dose de antibiótico.

\section{Colaborações}

Neiva LB; Fonseca CD; Watanabe M e Vattimo MFF participaram da concepção e projeto, análise e interpretação dos dados, redação do artigo e revisão crítica relevante do conteúdo intellectual e aprovação final da versão a ser publicada.

\section{Referências}

1. Pannu N, Nadim MK. An overview of drug-induced acute kidney injury. Crit Care Med. 2008; 36 (4 Suppl):S216-23.

2. Hermsen ED, Sullivan CJ, Rotschafer JC. Polymyxins: pharmacology, pharmacokinectics, pharmacodynamics and clinical applications. Infect Dis Clin North Am. 2003; 17(3); 545-62.

3. Arnold TM, Forrest GN, Messmer KJ. Polymyxin antibiotics for gramnegative infections. Am J HealthSyst Pharm. 2007; 64(8): 819-26.

4. Kwa AL, LimTP, Low JG, Hou J, Kurup A, Prince RA, Tam VH. Phamacokinectics of polymyxin B1 in patients with multidrug resistant Gram-negative bacterial infections. Diagn Microbial Infect Dis. 2008; 60(2):163-7.

5. Dezoti C, Watanabe M, Pinto CF, Neiva LB, Vattimo MF. Functional protection of heme-oxygenase-1 enzyme in ischemic and toxic acute kidney injury. Acta Paul Enferm. 2009; 22 (Especial-Nefrologia):490-3.

6. Havasi A, Borkan SC. Apoptosis and acute kidney injury. Kidney Int. 2011; 80(1):29-40.

7. Coico R. In vitro assays for mouse B and T cell function. Related isolation procedures and functional assays. In: Coligan JE, Kruisbeek AM, Margulies DH, Shevach EM, Strober W, editors.,Current protocols in immunology. Vol. 3.17. New York: John Wiley \& Sons, Inc.; 1995. p 1-33.

8. Filatov MV, Varfolomeeva EY. Active dissociation of Hoechst 33342 from DNA in living mammalian cells. Mutat Res. 1995; 327(1-2): 209-15.

9. Falagas ME, Kasiakou SK. Toxicity of polymyxins: a systematic review of the evidence from old and recent studies. Crit Care. 2006;10(1): R27.

10. Dollery C, editor. Therapeutic drugs. Edinburgh: Churchill Livingstone; 1991. Polymyxin B (sulphate); v. 2, pt. 2, p. 151-4.

11. Pedersen RS, Lonka L, Hansen HE. Acute renal failure caused by polymixin B containing ointment. Scand J Urol Nephrol. 1987; 21(2): 153-4.

12. Ouderkirk JP, Nord JA, Turett GS, Kislak JW. Polymyxin B nephrotoxicity and efficancy against nosocomial infections caused by multiresistant gram-negative bacteria. Antimicrob Agents Chemother. 2003; 47(8):2659-62.

13. Danner RL, Joiner KA, Rubin M, Patterson WH, Johnson N, Ayers KM, et al. Purification, Toxicity, and antiendotoxinactivity of polymyxin B nonapeptide. Antimicrob Agents Chemother. 1989; 33(9):1428-34. 